\title{
COVID-19 and Anxiety: A Review of Psychological Impacts of Infectious Disease Outbreaks
}

\author{
Mohammad Ali Fardin (iD) ${ }^{1}{ }^{*}$ \\ ${ }^{1}$ Department of Psychology, Zahedan Branch, Islamic Azad University, Zahedan, Iran \\ "Corresponding author: Department of Psychology, Zahedan Branch, Islamic Azad University, Zahedan, Iran. Tel: +98-9155401527, Email: fardinmohamadali@yahoo.com
}

Received 2020 March 16; Accepted 2020 March 25.

\begin{abstract}
Context: The advent of coronavirus disease 2019 (COVID-19) has caused confusion, changed people's living conditions, including commuting restrictions, fear of disease transmission, and closure of schools and businesses, and brought about devastating psychological impacts, like anxiety. However, most studies only have focused on clinical data.

Evidence Acquisition: In this short review, the psychological effects of COVID-19 and its association with anxiety were examined. Accordingly, the electronic databases, including PubMed, Medline, Elsevier, and Science Direct were reviewed for relevant studies that have conducted since 2007.

Results: The current study was carried out to indicate that COVID-19 has negative psychological problems other than mortality. A review of the studies performed in other parts of the world showed that COVID-19 has caused several psychological impacts, including increased anxiety.

Conclusions: By an increase in the prevalence rate of COVID-19 and its resulted restrictions, the level of anxiety increases, as well; therefore, raising public awareness of the disease and providing positive psychological programs in the media aimed at controlling stress can reduce anxiety in society.
\end{abstract}

Keywords: COVID-19, Anxiety, Psychological, Infectious Diseases, Outbreak

\section{Context}

The World Health Organization has reported several types of viral infections, and millions of people are at risk for these diseases in various ways worldwide (1). The coronavirus disease 2019 (COVID-19) epidemic is known as a general health crisis that has caused challenges for mental resilience and has been the biggest outbreak since the severe acute respiratory syndrome (SARS) outbreak in 2003 (2). COVID-19 was initially reported by China in late 2019 and had spread to 13 countries by January 24, 2020 (3). COVID19 as an emerging infectious disease was first identified in Wuhan (4). Its impacts have not yet been determined, as the observations and testing results are changing rapidly, leading to a high mortality rate. Among prevalent symptoms of this disease, cough, fever, shortness of breath, and sometimes diarrhea can be mentioned. Bats are thought to be the natural host of the virus (5).

In addition to endangering human health and consequently their deaths, COVID-19 imposes irreversible psychological impacts on human societies. For example, complete quarantine and commuting restrictions that prevent people from going out, fear of suffering from the disease, anxiety about losing loved ones, and more importantly, depression following losing friends and family are some of the issues people should deal with. The world has witnessed several widespread outbreaks of acute respiratory illnesses. For example, SARS as a communicable infectious disease spread in 2003; but, it was largely managed by quarantine measures. However, the effects of quarantine have never been investigated (6). The COVID-19 outbreak creates anxiety among people, especially in affected countries, and the media have huge impacts on increasing mental distress (7). For instance, some media have been using the term "end of the world" since the spread of the disease, leading to increased concern (8).

Some countries' social stability has seriously been affected by COVID-19 (9). In addition, the rate of distress among healthcare staff is higher compared with the general population, because they are more at risk for infection and transmission (7). The consequences of the disease outbreaks affecting all aspects of humans' lives have continued (10). The current epidemic of COVID-19 is serious resulting in a pandemic (11). Given that no research has yet 
been carried out in Iran to investigate the psychological impacts of COVID-19 and the rapid spread of the virus in different countries, the present study was conducted to review the studies on psychological impacts of COVID-19 and other infectious diseases worldwide.

\section{Evidence Acquisition}

In this short review, the psychological impacts of COVID-19 and its association with anxiety were examined. Accordingly, 10 selected studies that have been conducted since 2007 were reviewed using electronic databases, i.e., PubMed, Medline, Elsevier, and Science Direct.

\section{Results}

In a cross-sectional study, Wang et al. (2) evaluated psychological impacts, depression, stress, and anxiety at the beginning of the COVID-19 outbreak. In this study, 1210 participants from 194 cities in China answered an online questionnaire. The author showed that $53.8 \%$ of these people experienced severe psychological impacts of the outbreak. Moreover, $16.5 \%, 28.8 \%$, and $8.1 \%$ of the respondents reported moderate to severe levels of depression, anxiety, and stress, respectively (2).

Al-Rabiaah et al. (7) explored the impacts of the Middle East respiratory syndrome coronavirus (MERS-CoV) epidemic by examining medical students and found that all of these students experienced stress; however, female students were found with higher levels of stress (7).

$\mathrm{Xu}$ et al. (11) figured out that anxiety and fear were very prevalent among patients with COVID-19. Hence, they conducted accurate assessments and provided warnings to deal with this psychological crisis by providing rehabilitation programs using traditional Chinese medicine (11).

In a study that examined the psychological impacts of quarantine during the SARS outbreak conducted on 129 people in Canada, Hawryluck et al. (6) indicated a high prevalence of psychological distress, post-traumatic stress disorder (PTSD) rate of $28.9 \%$ and a depression prevalence of $31.2 \%$. Furthermore, there was a significant correlation between the duration of quarantine and the prevalence of PTSD symptoms; therefore, direct contact with a person with SARS exacerbated the symptoms of depression and PTSD (6). Lee et al. (12) evaluated the psychological impacts of the MERS outbreak and found that PTSD symptoms were very high among hospital staff even many years after the outbreak. AlNajjar et al. (13) in a study that investigated the psychobehavioural responses of adults to the MERS-CoV epidemic in Jeddah shopping centers in western Saudi Arabia, found that anxiety levels were significantly associated with increased perception of susceptibility to infection and social avoidance behaviors related to travel and being in public places.

Van Bortel et al. (14) assessed the psychological impacts of the Ebola outbreak on people, society, and the world. This disease infected nearly 28,000 people from 2013 to 2016 and led to 11,000 deaths. The results demonstrated that people experienced severe psychological trauma due to observing other people's death and having a fear of death (14).

Rubin et al. (15) conducted a study to examine the impacts of communication and media at the time of the influenza A(H1N1; swine flu) outbreak on the general population in the UK and concluded that being exposed to media and publicity related to the disease increased the purchase of disinfectant gels and boosted concerns about and avoidance of public transport vehicles. McAlonan et al. (16) examined the immediate effects of emerging infectious diseases on healthcare staff and found that people who were directly at the risk for SARS reported high rates of depression and anxiety in addition to chronic stress. Tucci et al. (17) explored the impacts of emerging infectious diseases and found that different infectious diseases have significant associations with obsessive-compulsive disorders and mental illness.

\section{Conclusions}

Although the World Health Organization has considered the measures taken by the Chinese government effective and positive, there is still a great need for making sustained and serious efforts to tackle such diseases in the future (4); because the emergence of another type of human disease from different families of viruses, previously regarded as non-dangerous, can become a constant challenge (5). Currently, at the peak of the COVID-19 outbreak, there is no thorough information on the psychological impacts of the disease on people, and people experience severe negative emotions due to the closure of schools and businesses (2). It has indicated that the prevalence of psychological harm caused by the spread of communicable diseases in society is very considerable. For example, people's fear and anxiety can be increased due to the loss of trust in mental health services (14). Although extensive restrictions, such as the prohibition of national and international travel that reflects a new type of quarantine are effective in controlling and managing the disease, they have negative psychological impacts on people. Anxiety about food shortages is more considerable. Moreover, spreading rumors has negative psychological impacts (8). Therefore, psychiatric interventions are essential during infectious disease outbreaks with high mortality rate (12). 
The results of this study showed the psychological impacts of communicable diseases, such as COVID-19 on the general population, especially on vulnerable groups. Therefore, designing psychological interventions to improve mental health during epidemics is essential. Raising people's awareness about the measures taken by the government to counter the spread of rumors, applying optional to mandatory restrictions, and raising public awareness by providing information on the patients' recovery process can reduce anxiety in society.

\section{Footnotes}

Authors' Contribution: Mohammad Ali Fardin provided the research idea, searched for previous relevant articles, prepared the paper, and edited the paper and references.

Conflict of Interests: The authors declared no conflicts of interest.

Funding/Support: This study was not supported by any organization.

\section{References}

1. Al-Hazmi A. Challenges presented by MERS corona virus, and SARS corona virus to global health. Saudi J Biol Sci. 2016;23(4):507-11. doi: 10.1016/j.sjbs.2016.02.019. [PubMed: 27298584]. [PubMed Central: PMC4890194].

2. Wang C, Pan R, Wan X, Tan Y, Xu L, Ho CS, et al. Immediate psychological responses and associated factors during the initial stage of the 2019 coronavirus disease (COVID-19) Epidemic among the general population in China. Int J Environ Res Public Health. 2020;17(5). doi: 10.3390/ijerph17051729. [PubMed: 32155789]. [PubMed Central: PMC7084952].

3. Nishiura H, Jung SM, Linton NM, Kinoshita R, Yang Y, Hayashi K, et al. The extent of transmission of novel coronavirus in Wuhan, China, 2020.JClin Med.2020;9(2). doi:10.3390/jcm9020330. [PubMed: 31991628]. [PubMed Central: PMC7073674].

4. Yang HY, Duan GC. [Analysis on the epidemic factors for the corona virus disease]. Zhonghua Yu Fang Yi Xue Za Zhi. 2020;54(0). Chinese. E021. doi: 10.3760/cma.j.cn112150-20200227-00196. [PubMed: 32125129].

5. Paules CI, Marston HD, Fauci AS. Coronavirus infections-more than just the common cold. JAMA. 2020. doi: 10.1001/jama.2020.0757. [PubMed: 31971553].
6. Hawryluck L, Gold WL, Robinson S, Pogorski S, Galea S, Styra R. SARS control and psychological effects of quarantine, Toronto, Canada. Emerg Infect Dis. 2004;10(7):1206-12. doi: 10.3201/eid1007.030703. [PubMed: 15324539]. [PubMed Central: PMC3323345].

7. Al-Rabiaah A, Temsah MH, Al-Eyadhy AA, Hasan GM, Al-Zamil F, Al-Subaie $S$, et al. Middle East respiratory syndrome-corona virus (MERS-CoV) associated stress among medical students at a university teaching hospital in Saudi Arabia. J Infect Public Health. 2020. doi: 10.1016/j.jiph.2020.01.005. [PubMed: 32001194].

8. Rubin GJ, Wessely S. The psychological effects of quarantining a city. BMJ. 2020;368:m313. doi: 10.1136/bmj.m313. [PubMed: 31992552].

9. Chen C, Zhang XR, Ju ZY, He WF. [Advances in the research of cytokine storm mechanism induced by corona virus disease 2019 and the corresponding immunotherapies]. Zhonghua Shao Shang Za Zhi. 2020;36(0). Chinese. E005. doi: 10.3760/cma.j.cn501120-2020022400088. [PubMed: 32114747].

10. Makamure M, Makamure M, Mendiola W, Renteria D, Repp M, Willden A. A review of critical care nursing and disease outbreak preparedness. Dimens Crit Care Nurs. 2013;32(4):157-61. doi: 10.1097/DCC.0b013e318299801f. [PubMed: 23759903].

11. Xu K, Cai H, Shen Y, Ni Q, Chen Y, Hu S, et al. [Management of corona virus disease-19 (COVID-19): The Zhejiang experience]. Zhejiang DaXue Xue Bao Yi Xue Ban. 2020;49(1). [PubMed: 32096367].

12. Lee SM, Kang WS, Cho AR, Kim T, Park JK. Psychological impact of the 2015 MERS outbreak on hospital workers and quarantined hemodialysis patients. Compr Psychiatry. 2018;87:123-7. doi: 10.1016/j.comppsych.2018.10.003. [PubMed: 30343247]. [PubMed Central: PMC7094631].

13. AlNajjar NS, Attar LM, Farahat FM, AlThaqafi A. Psychobehavioural responses to the 2014 Middle East respiratory syndrome-novel corona virus (MERS CoV) among adults in two shopping malls in Jeddah, western Saudi Arabia. East Mediterr Health J. 2017;22(11):817-23. doi: 10.26719/2016.22.11.817. [PubMed: 28177112].

14. Van Bortel T, Basnayake A, Wurie F, Jambai M, Koroma AS, Muana AT, et al. Psychosocial effects of an Ebola outbreak at individual, community and international levels. Bull World Health Organ. 2016;94(3):2104. doi: 10.2471/BLT.15.158543. [PubMed: 26966332]. [PubMed Central: PMC4773931].

15. Rubin GJ, Potts HW, Michie S. The impact of communications about swine flu (influenza A H1N1v) on public responses to the outbreak: Results from 36 national telephone surveys in the UK. Health Technol Assess. 2010;14(34):183-266. doi: 10.3310/hta14340-03. [PubMed: 20630124].

16. McAlonan GM, Lee AM, Cheung V, Cheung C, Tsang KW, Sham PC, et al. Immediate and sustained psychological impact of an emerging infectious disease outbreak on health care workers. Can J Psychiatry. 2007;52(4):241-7. doi: 10.1177/070674370705200406. [PubMed: 17500305].

17. Tucci V, Moukaddam N, Meadows J, Shah S, Galwankar SC, Kapur GB. The forgotten plague: Psychiatric manifestations of Ebola, Zika, and emerging infectious diseases. J Glob Infect Dis. 2017;9(4):151-6. doi: 10.4103/jgid.jgid_66_17. [PubMed: 29302150]. [PubMed Central: PMC5750439]. 